\title{
The collapse of sensemaking at Yarnell Hill: the effects of endogenous ecological chaos on enactment
}

\author{
Dan Parrish C.S.C. \\ Pamplin School of Business, University of Portland, Portland, Oregon, USA \\ Timothy S. Clark \\ Independent Researcher, Prescott, Arizona, USA, and \\ Samuel S. Holloway \\ Pamplin School of Business, University of Portland, Portland, Oregon, USA
}

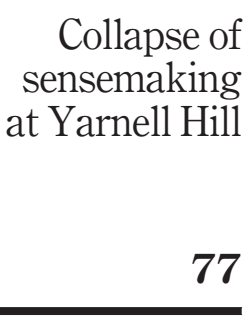

Received 14 August 2019 Revised 12 February 2020 30 June 2020 Accepted 7 July 2020

\begin{abstract}
Purpose - Since Weick's (1993) seminal Mann Gulch paper articulated a collapse of sensemaking, scholars have repeatedly investigated sensemaking downstream of enactment. Motivated by another wildland firefighting tragedy, the tragic loss of 19 firefighters in Arizona in 2013, this study aims to look at enactment itself and reveals that the endogenous creation and re-creation of the wildland fire caused a fatal feedback loop of "trigger traps" leading to perpetual enactment that short-circuited sensemaking. Wildland fires can have unpredictable consequences, which triggers in individual sensemakers a fatal and continuous return to the beginning of the sensemaking process.
\end{abstract}

Design/methodology/approach - This paper's approach is a case study based on a textual analysis of sources investigating the 2013 Yarnell Hill fire. The authors also carefully compared the Yarnell Hill and Mann Gulch disasters in search of breakdowns in sensemaking that could help us understand why we continue to lose firefighters in the line of duty.

Findings - The simultaneously volatile and complex environment at Yarnell illustrates sensemaking antecedents to the study of enactment. The findings suggest ways that organizations - those fighting wildfire or those fighting a global pandemic - can avoid getting trapped in the early stages of enactment and can retain resilience in their sensemaking.

Originality/value - This paper introduces the concept of "trigger traps" to help explain the fatal feedback loop of repeated environmental triggers in the early stages of sensemaking in volatile environments.

Keywords Complexity, Volatility, Organizational sensemaking, Wildland firefighting

Paper type Research paper

(C) Dan Parrish C.S.C., Timothy S. Clark and Samuel S. Holloway. Published in European Journal of Management Studies. Published by Emerald Publishing Limited. This article is published under the Creative Commons Attribution (CC BY 4.0) licence. Anyone may reproduce, distribute, translate and create derivative works of this article (for both commercial and non-commercial purposes), subject to full attribution to the original publication and authors. The full terms of this licence maybe seen at http://creativecommons.org/licences/by/4.0/legalcode

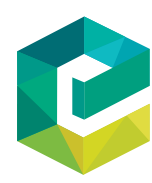

European Journal of Management Studies

Vol. 25 No. 2,2020

pp. $77-9$ 2183-4172 DOI 10.1108/EJMS-10-2020-005 
EJMS

25,2

\section{Introduction}

The 19 were fathers, husbands, brothers, and sons and all were neighbors within the small city of Prescott, Arizona. Their deaths on June 30, 2013 comprised the worst single-day loss of firefighters since September 11, 2001, and devastated their families and their entire community. The hotshot crew became trapped after crossing an unburnt hillside, rushing toward a pre-determined safety zone that was just a quarter of a mile further. Blocked by a ridge from seeing the wind-whipped wall of fire approaching, they were soon overrun. The lone survivor of the team, who had been stationed as a lookout a short distance away, barely escaped before his area, too, was overrun. The major motion picture released soon after, Only the Brave (Kosinski, Flynn, Nolan, \& Singer, 2017), dramatizes the lead-up and deaths of these men with accuracy and a heroic respectfulness rarely so gratefully acknowledged by victims' survivors.

What is particularly devastating about the tragedy, from both human and organizational perspectives, is the fact that the men of Granite Mountain inter-agency hotshot crew (IHC) were moving from safety to safety down the side of Yarnell Hill - they had been "in the black," (U.S. Forest Service, 2013, p. 1) a burned out portion of the landscape with no additional unburnt fuel - and were repositioning to a "bomb proof" homestead (U.S. Forest Service, 2013, p. 52). What organizational breakdown led them, instead, directly into the path of the inferno? Why did not they radio their exact location to Incident Command so that the air tanker literally circling in the sky above them could have dropped lifesaving retardant? What went wrong that turbulent June day, and how might we continue to fortify organizational resiliency to prevent future catastrophes, whether in wildland firefighting crews or in any other organizations that face environmental volatility?

This study explores the antecedents to enactment and how endogenous and constant reinvention of environmental conditions can short-circuit organizational sensemaking. We have a good understanding of how organizational sensemaking operates, from representations such as Weick's (1979) early model of the four processes of organizing (ecological change, enactment, selection, and retention) to later models such as Jennings and Greenwood's (2003) that illustrate clearly the various feedback loops in the process and include the seven primary properties of sensemaking (Weick, 2001). What is missing in these models is an appreciation of pitfalls that, especially in chaotic situations, can result in systemic failure and even tragedy.

The literature on sensemaking in wildland firefighting spans several decades - as scholars have broadened the understanding of organizational reliability, they have worked to provide more reliable organizing tactics that would save firefighter lives. Various scholars joined the USDA Forest Service for a four day workshop entitled, "Managing the unexpected in prescribed fire use operations: A workshop on the high reliability organization" (Keller, Weick, Sutcliffe, Saveland, Lahey, Thomas et al., 2004), in which they revisited the site of the 2000 Cerro Grande Prescribed Fire (Lonnie, Thompson, Loach, Delfin, \& Przybylek, 2000). The investigation report on the Yarnell Hill incident (U.S. Forest Service, 2013) includes a lengthy consideration of both sensemaking and reliability; likewise, scholars have interrogated Yarnell through the same lenses (Ishak \& Williams, 2017; Williams \& Ishak, 2018). This and other research is motivated by the hope Weick (1993) expressed over 25 years ago that derived knowledge from Mann Gulch - and, in the intervening years, other research - might "forestall similar disasters in other organizations," (p. 634).

Yet we continue to lose firefighters in the line of duty. This prompts reconsideration of what is known about sensemaking, to approach Weick's goal of preventing future disasters, not just in flaming forests, but in chaotic offices and organizations as well. This added 
nuance for models of organizational sensemaking could help us to better understand the unique challenges of high levels of environmental volatility, which might be especially helpful for wildland firefighting.

Beginning with Jennings and Greenwood's (2003) model of sensemaking, our research introduces a new feedback loop not previously considered. A close read of the investigation report (U.S. Forest Service, 2013) identifies a repeated and fatal feedback loop of "trigger traps," caused by the endogenous creation and re-creation of the wildland fire itself. As the hotshots' sensemaking was repeatedly triggered by the volatile and constantly changing weather, they were unable to move into the latter stages of sensemaking, especially retention. The constant triggering trapped them in the initial stages of sensemaking, far from the relative safety that a clear understanding of the environment might provide. This new finding - a feedback loop of trigger traps upstream from enactment - provides a theoretical contribution for understanding the intersection of environmental volatility and complexity, particularly in the early enactment stage of sensemaking.

To summarize, our contribution develops new understanding of the ways volatile and complex environments can confine sensemakers to the early stages of enactment. We assert that this will not only help organizations (including wildland fire fighters) avoid future tragedies but also build resiliency at team and organizational levels. Although few organizational settings may consist of similar levels of volatility, a greater appreciation of potential traps could lead to more reliable functioning in any organization confronting environmental complexity and unpredictability.

\section{Review of relevant literature \\ Organizational sensemaking}

Organizational sensemaking is a framework that describes how we understand the world around us, especially events and situations that are novel or surprising. Maitlis and Christianson (2014) define sensemaking as: "a process, prompted by violated expectations, that involves attending to and bracketing cues in the environment, creating intersubjective meaning through cycles of interpretation and action, and thereby enacting a more ordered environment from which further cues can be drawn" (p. 67).

Notable in this definition is the phrase "violated expectations." Although sensemaking is ongoing and constant - whereby all people are always extracting environmental cues and creating meaning whenever they are conscious - it is most obvious that we are engaged in sensemaking when environmental triggers violate our expectations.

Weick (1995) identifies seven observable properties of sensemaking. He argues that sensemaking is: social; grounded in identity construction; retrospective; focused on and by extracted cues; ongoing; driven by plausibility rather than accuracy; and enactive of sensible environments. Enactment describes the way that "people often produce part of the environment they face" (p. 30). In other words, we are not wholly objective, disengaged observers of the environments in which we exist. Rather, our presence in environments, as well as the actions and decisions we make, alter the construction of the environment in ways that can even constrain us. For example, Schabram and Maitlis (2017) found that the ways workers emotionally respond to their work can enact different future work environments. Similarly, enactment can lead to negative assumptions being solidified as threats to physicians' workplace wellbeing (Heath \& Porter, 2019), whereas clarity of goals and familiarity within groups can enact higher levels of performance for wildland firefighters (Barton et al., 2015).

Understanding enactment is crucial for analyzing crises and their antecedent conditions. For instance, in the Bhopal chemical-plant disaster in India (Weick, 2010), a series of personal, procedural, and organizational failures - such as failing to fix leaky valves -
Collapse of sensemaking at Yarnell Hill 
EJMS

25,2

contributed to a colossal explosion that killed thousands of people. Indeed, a common formula for sensemaking is, "How can I know what I think until I see what I say?" (Weick, 1979, p. 133). Meaning-making does not begin until one speaks or takes action - this is enactment. Whether exploring aviation disasters (Berthod \& Müller-Seitz, 2018), the police killing of an innocent civilian suspected of terrorism (Cornelissen, Mantere, \& Vaara, 2014), or a gas pipeline explosion (Gephart, 1993), sensemaking research is often situated in situations of crisis or chaos, as we search for clues to help explain and prevent organizational failures.

\section{High reliability}

An important focus within the sensemaking literature is high-reliability organizations (HROs). HROs are organizations that must always operate at a high rate of reliability, such as the air traffic control system, nuclear power plants, or research laboratories that deal with hazardous materials. Lessons learned in situations where failure is not acceptable can help us increase reliability in less critical organizational settings. Scholars have identified five features of high reliability: preoccupation with failure, reluctance to simplify interpretations, sensitivity to operations, commitment to resilience, and deference to expertise (Weick and Sutcliffe, 2007).

Cultivating a reluctance to simplify is important for maintaining requisite variety within organizations. Weick (1995) explains:

One of my favorite conceptual tools, the notion of requisite variety, is modeled after a carpenter's tool called a contour gauge... . a set of sensors that registers the patterns of a solid surface when it is pressed against that surface. The gauge allows the carpenter to transfer that pattern to another surface where it can be traced and duplicated. (p. 34)

Contour gauges with fewer, coarser pins are only able to approximate contours that could be much more precisely sensed with gauges with finer and more numerous pins. Gauges with finer and more numerous pins have greater requisite variety, making them better tools for carpenters tasked with matching a complex original design, such as an ornate molding. Organizations that operate with high reliability likewise resist the temptation to simplify, "because simplification obscures unwanted, unanticipated, unexplainable details and in doing so, increases the likelihood of unreliable performance" (Weick \& Sutcliffe, 2015, p. 645).

\section{Volatility}

A framework for characterizing difficult environments is VUCA, an acronym for volatility, uncertainty, complexity, and ambiguity. VUCA was originally formulated for military purposes (Murphy, 1997) and is "used to describe an environment which defies confident diagnosis" (Bennett \& Lemoine, 2014, p. 311). The first facet of VUCA is volatility, which can be understood as "relatively unstable change; information is available and the situation is understandable, but change is frequent and sometimes unpredictable" (Bennett \& Lemoine, 2014, p. 313).

Reducing volatility has long been a key component of organizing for high reliability objectives. Bigley and Roberts (2001) found that "structuring mechanisms, organizational support for constrained improvisation, and cognition management methods," (p. 1282) allowed a fire department to provide "exceptional organizational reliability under volatile environmental conditions" (p. 1282). Other research has explored efforts to combat volatility in oil companies through strategic planning (Grant, 2003) and in entrepreneurial ventures through dynamic capabilities (Zahra, Sapienza, \& Davidsson, 2006). Research has also 
examined the impact of volatility on sensemaking itself. Parrish (2019) found that high environmental volatility can lead to restricted communication, which results in the reduction of requisite variety. This restriction is precisely the wrong reaction, since volatile situations require the extraction of a broad range of social cues.

Volatility also influences group behavior within large organizations. Ahmadjian and Robinson (2001) studied downsizing in Japanese companies in the 1990s and identified an isomorphic "safety in numbers" effect. As the country dealt with the effects of an economic downturn, companies began breaking away from the institutionalized practice of lifelong employment by downsizing. The authors found that although firms encountered social and institutional pressures not to end lifelong employment, as more and more companies began downsizing, many found safety in numbers that would blunt criticism and legitimize their choice to downsize.

\section{Complexity}

Another facet of VUCA which is prominent in the Yarnell Hill tragedy is complexity - which characterizes environments that include "many interconnected parts forming an elaborate network of information and procedures; often multiform and convoluted, but not necessarily involving change" (Bennett \& Lemoine, 2014, p. 313). Complex environments can be difficult to understand and interpret, leading sensemakers to seek "inter-organizational collaboration ... to pool their expertise to explore strategic issues" (Seidl \& Werle, 2018, p. 830).

A primary reason why organizational complexity is difficult to manage is because it "inevitably yields unexpected interactions between independent failures" (Rijpma, 1997, p. 15). In complex systems or organizations, relationships between units and subsystems can be difficult to fully grasp, which can lead to unexpected interactions and system breakdowns. Sometimes a breakdown can lead to emotional distress that short-circuits sensemaking, as in the fateful case of Flight Air France 447 which disappeared over the Atlantic Ocean in 2009 (Berthod \& Müller-Seitz, 2018). In other situations, sensemakers create novel routines to deal with increasing complexity, although it can have the unintended effect of increasing equivocality, as in the wrongful shooting of a suspected terrorist in London (Colville, Pye, \& Carter, 2013). Adaptive complex systems may even exist at the "edge of chaos" (Brown \& Eisenhardt, 1997, p. 29) in a state of constant change, further complicating efforts to make sense of them.

One danger experienced by sensemakers confronting complex situations is the introduction of "too much equivocality from too many different sensemakers" (Maitlis \& Sonenshein, 2010, p. 572). In other words, those seeking requisite variety in response to complex environments can introduce additional variety, leading to an overwhelming multiplicity of perspectives on the issue at hand. Complex situations, especially instances of crisis or change, can also elicit "emotional expressions [that] can be contagious, significantly affecting group sensemaking processes" (Maitlis \& Sonenshein, 2010, p. 568). A method for combatting the negative effects of emotional expressions is mindful organizing (Weick \& Sutcliffe, 2007): "a collective behavioral capability to detect and correct errors and adapt to unexpected events” (Vogus, Rothman, Sutcliffe, \& Weick, 2014, p. 592). Such mindfulness can help sensemakers in complex environments to "be prosocially motivated to protect their colleagues and stakeholders from the potential harm inherent in their work (Vogus, et al., 2014, p. 593).

Alongside volatility and complexity, VUCA also includes uncertainty: "a lack of knowledge as to whether an event will have meaningful ramifications; cause and effect are understood, but it is unknown if an event will create significant change;" and ambiguity: "a lack of knowledge as to 'the basic rules of the game'; cause and effect are not understood and 
EJMS

25,2

there is no precedent for making predictions as to what to expect" (Bennett \& Lemoine, 2014, p. 313).

Though these characteristics may have been factors in the Yarnell Hill tragedy, our analysis focuses on the extraordinary volatility and complexity present that fateful day.

\section{Methodology}

Our approach is a case study based on a textual analysis of sources investigating the 2013 Yarnell Hill fire, primarily the Serious Accident Investigation Report (U.S. Forest Service, 2013), in addition to various books that tell the fateful story from various perspectives (Dickman, 2015; McDonough \& Talty, 2016; Mohit, Kelso, \& Florman, 2014/2016; Santos, 2016). Informed by the tradition of examining sensemaking in wildland firefighting that dates to Weick's (1993) seminal analysis of Mann Gulch, we looked for breakdowns that could help explain the deaths of the 19 Granite Mountain hotshots in 2013. We also carefully compared the Yarnell Hill and Mann Gulch disasters in search of breakdowns in sensemaking that could help us understand why we have not been able to "forestall similar disasters [to Mann Gulch] in other organizations," (Weick, 1993, p. 634) and continue to lose firefighters in the line of duty.

Management theory offers potential explanations for Yarnell, based on the sensemaking activities of the firefighters and their superiors. Organizational sensemaking relies upon individuals developing a process model of enactment, selection, and retention, as well as various feedback mechanisms downstream of the initial enacted environment (Jennings and Greenwood, 2003; Weick, 1988). We, too, fell into this familiar pattern for several years, as we fruitlessly sought to add to the academic knowledge with our exploration of the Yarnell tragedy. We kept looking downstream of enactment and examined in detail the literature for some theoretical contribution that we could glean from Yarnell which could potentially save firefighters' lives. However, in light of Stackman and Hannah (2017), we realized that even an exhaustive review of existing management literature might not ever fully address the problems of sensemaking in wildland firefighting.

We recognized that we had fallen into the trap of being journalistic technicians, instead of genuine scholars driven by their curiosity (Alvesson \& Sandberg, 2013). From this realization came a grim truth: to truly find a new idea we had to "drop [our] tools" (Weick, 1993, p. 629) and turn our examination to antecedents: wildland fires themselves. This decision proved fruitful from a theory-development perspective, and heartbreaking from a personal one (Whiteman, 2010), as we delved deeper into the story of the 19 lives suddenly lost at Yarnell Hill.

Recent research from fire science (Heilman, Bian, Clark, \& Zhong, 2019) indicated to us that a key challenge at Yarnell Hill was an extreme fire that changed the weather around itself faster than those changes could be grasped and enacted upon by the firefighters or incident command. In such cases of simultaneous fire and weather volatility, the conditions within and surrounding an intense fire can change faster than firefighters can understand them. We hypothesized that such extreme volatility could short-circuit sensemaking by locking sensemakers into an initial enactment loop, preventing them from moving to later sensemaking stages of retention. Here we found a plausible explanation for how Granite Mountain found itself suddenly trapped in a zone they believed to have been safe for passage. This insight became the key for better understanding the enactment loop at the beginning of organizational sensemaking. With this important nuance in hand, we then compared our findings with the literature on high reliability organizing to identify ways to further strengthen organizational resiliency in firefighting and in broader contexts. 
Our analysis consisted of a study of the Serious Accident Investigation Report (U.S. Forest Service, 2013), with comparison and contrast between the Yarnell Hill and Mann Gulch (Weick, 1993) fires. Though the accident report stops short of assigning guilt, stating, "The Team found no indication of negligence, reckless actions, or violations of policy or protocol" (U.S. Forest Service, 2013, p. 43), a number of troubling and puzzling details about the accident stand out in the report. We highlighted these details and analyzed the sensemaking literature, in particular the literature on high reliability, in search of explanations. We characterized the environmental conditions at Yarnell according to the VUCA framework (Bennett \& Lemoine, 2014; Murphy, 1997) creating a two by two model for understanding the interplay of volatility and complexity. Finally, we revisited a theoretical model of sensemaking (Jennings \& Greenwood, 2003) to identify specific breakdowns in sensemaking that might explain the collapse of reliability at Yarnell Hill.

\section{Analysis}

\section{Sensemaking and wildland firefighting settings}

Our inquiry begins by comparing Mann Gulch and Yarnell Hill to detail similarities and differences. The crew that jumped into Mann Gulch in 1949 was an ad hoc team - a "small temporary [outfit] in which the stakes are high and where foul-ups can have serious consequences" (Weick, 1993, p. 632). On Yarnell Hill, in contrast, "The Granite Mountain IHC was a fully qualified, staffed, and trained hotshot crew. They were current with the required training and met work/rest guidelines" (U.S. Forest Service, 2013, p. 2). Whereas the Mann Gulch crew was a makeshift team, brought together reactively to fight that specific fire, modern firefighting crews like Granite Mountain are tight units that train together and are deployed together - remaining largely intact throughout successive fire seasons.

Nevertheless, we see a similar ad hoc problem when these highly trained modern crews are assigned to work alongside other crews (often numbering hundreds or even thousands of other firefighters) on modern fires. Although individual firefighting crews are tightly knit, deployment alongside other crews with whom they have no prior relationships might bring to the surface some of the same ad hoc problems, such as the "inability for intergroup structures to form" (Weick, 1993, p. 648). One of the primary indicators of such malformed intergroup structures on Yarnell Hill is the fact that:

Few people understood Granite Mountain's intentions, movements, and location, once they left the black [the safety of the burnt ground where no additional tinder remained]. The [Investigation] Team believes this is due to brief, informal, and vague radio transmissions and talkarounds that can occur during wildland fire communications. (U.S. Forest Service, 2013, p. 3)

A communication breakdown of this severity is symptomatic of an ad hoc collection of teams with underdeveloped structures and of limitations in protocols and technologies that may have dissuaded better communication.

Though in both settings we identify significant volatility, with the fires quickly and unexpectedly changing course - to deadly effect - one of the biggest differences between Mann Gulch and Yarnell Hill is the sheer complexity of the fires. Mann Gulch was thought to be a classic "10:00" fire to which a small group of smokejumpers were dispatched to a remote wilderness to contain the blaze by 10:00 a.m. the following morning. In contrast, the operation at Yarnell Hill included hundreds of firefighters, numerous air tankers and helicopters, and a complex command system to coordinate it all. Hundreds of structures in the nearby town of Yarnell, Arizona, were at risk, heightening the sense of urgency and greatly increasing the difficulty of managing the firefighting operation. Worsening weather conditions and changing reports about wind speed and direction further complicated the 
EJMS

25,2

environment. Finally, limited radio channels available for the multitude of firefighters led to diminished communication. Thus, the extent to which the Yarnell Hill fire was more complex than Mann Gulch and could be analogous to the increased complexity of contemporary workplaces and team processes between 1949 and today.

At Yarnell, communications difficulties compounded the ever-present complexity. According to the U.S. Forest Service (2013), some radios "were not equipped with appropriate tone guards," (p. 2) which made communication difficult; radio traffic on the seven available radio bands was "heavy during critical times on the fire" (p. 2). During the half hour leading up to the fatalities, Command could not verify the location of the Granite Mountain IHC, having "almost no direct information for them" (p. 1). Could these communication breakdowns have been due to the combined environmental volatility and complexity and the ways that affected radio usage during the fire? It is not uncommon for firefighters on large, complex fires to restrict radio communication by engaging in "brief, informal, and vague radio transmissions and talkarounds" (p. 3); however, this phenomenon had heightened and resulted in tragic effects in this instance.

In the Yarnell Hill incident, confusion about the hotshots' specific location resulted from radio transmissions being restricted to brief and informal statements, resulting in ambiguity for the Incident Command Post, which is responsible for updating firefighter locations and deploying resources to the fire. Because they were moving from safety to safety (from "the black" to a "bomb proof" location), the Granite Mountain team may not have felt the need to radio their location, in the hopes of reducing the overall amount of radio communication. This had the tragic effect of restricting cues for managers at the Incident Command Post in making sense of the complex dance of fire and firefighters. A tragic example of this restriction in communication is the fact that while Granite Mountain IHC succumbed to the flames below, a VLAT (very large air tanker) full of 11,400 gallons of fire suppressant was circling in the area - however, its crew was uncertain where the IHC was located and whether they even needed assistance at all (U.S. Forest Service, 2013, pp. 27-29).

Volatility is a common factor in firefighting. Complexity, in tandem, can make firefighting operations even more problematic. "In a rapidly escalating fire environment, firefighters simultaneously try to make sense of what the fire is doing and how the incident organization is changing" (U.S. Forest Service, 2013, p. 58). In other words, as a fire changes and grows, firefighters' sensemaking must evolve to keep up with the changing complexity of the fire itself. In addition, how they organize their firefighting efforts must continually change to meet the fire with appropriate resources in the right locations, and this may be restricted by forces beyond their control. Both the fire and the firefighting operation are constantly in flux, increasing the overall complexity of the effort. This relationship between volatility and complexity informs our development of Figure 1, explained in detail below.

To classify the various kinds of wildland fires, we incorporated the Incident Command Management Teams (IMT) designation, which is a standard system for classifying fire management needs from the National Park Service. As shown in Table 1, these classifications vary according to the complexity of the management team needed to suppress the fires. We found these standards mapped quite directly onto our fire classifications as follows. The system mirrors wildfire complexity and ranges from Type $5-$ low complexity, "very small wildland fire" - to Type 1 - high complexity, "large number of personnel and equipment" (Wildland Fire: Incident Command System Levels, 2017). Fires that generally exhibit low volatility - which means that change is relatively infrequent and generally predictable - are presented in the left-hand column of Figure 1 and are positioned according to their complexity (high and low). These fires present relatively low danger and are generally less difficult to manage. Small, prescribed fires tend to be carefully monitored and 


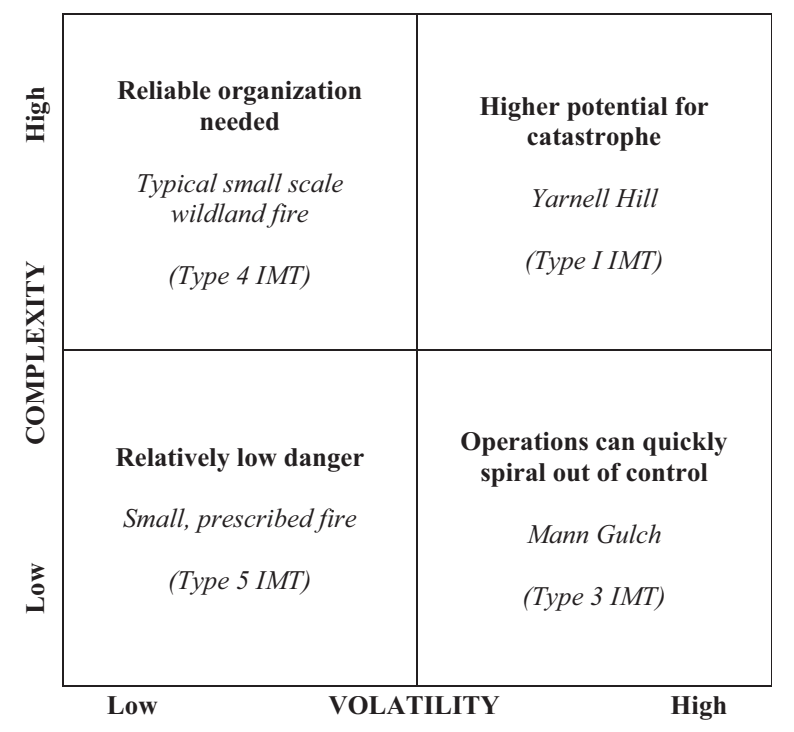

Source: Adapted from "Wildland Fire: Incident Command System Levels" (2017)

\section{Collapse of sensemaking at Yarnell Hill}

Figure 1.

Model of the effects of simultaneous volatility and complexity on sensemaking in wildland firefighting scenarios

\begin{tabular}{lll}
\hline Level & Complexity & Characteristics \\
\hline Type 5 & Very low & $\begin{array}{l}\text { Short duration; few resources assigned } \\
\text { Incident Command leads all operations, logistics, } \\
\text { planning, and finance functions; several individuals } \\
\text { or a single strike team }\end{array}$ \\
Type 3 & Moderate & $\begin{array}{l}\text { Resources may include several task forces or strike } \\
\text { teams; more extensive incident command structure } \\
\text { Large number of resources deployed; base camp } \\
\text { established; significant logistical support }\end{array}$ \\
Type 2 & High & $\begin{array}{l}\text { Multi-agency and national resources; large number } \\
\text { of personnel and equipment assigned to the incident }\end{array}$
\end{tabular}

Source: Adapted from (Wildland Fire: Incident Command System Levels, 2017)

Table 1.

Types of incident command management teams

can include just one standard Type 5 firefighting crew. More complex are typical small-scale wildland fires - characterized by low volatility, perhaps due, in part, to fair weather or even terrain. They require a more complex Type 4 firefighting response, including coordination by a central command unit.

Fires that generally exhibit high volatility - characterized by frequent and unpredictable change - are presented in the right-hand column, similarly according to high and low complexity. While the Mann Gulch fire was volatile, with operations quickly spiraling out of control and leading to the deaths of 13 of the 16 firefighters, the firefighting operation was not complex, consisting of just one crew of Type 3 smokejumpers. In contrast, the Yarnell Hill fire consisted of 
EJMS

25,2

86

hundreds of Type 1 firefighters and hotshots and a wide array of support resources, with weather and terrain conditions that contributed to very unpredictable change. This combination of high volatility and high complexity resulted in a firefighting operation that had a higher potential for catastrophe; indeed, 19 men lost their lives in the blaze.

It is in situations of complexity with simultaneous high volatility where we most often see firefighting tragedies, including both Mann Gulch and Yarnell Hill, as well as the significant loss of structures, such as in Cerro Grande (Lonnie, Thompson, Loach, Delfin, \& Przybylek, 2000) and the deaths of 14 firefighters in the South Canyon Fire (Rosenkrance, Reimers, Johnson, Webb, Graber, Clarkson et al., 1994). When volatility is low (see the left column of Figure 1), meaning that change is relatively predictable and stable, firefighters' sensemaking tends to be more reliable - resulting in far fewer losses of structures and human life. When change is stable and predictable, the sensemaking needs of the situation are greatly reduced. In this condition, instead of expending energy asking "What's the story" (Weick, 2008, para. 1), firefighters can focus their sensemaking on managing and fighting the fires. However, in situations of high volatility, characterized by unpredictable and unstable change, firefighters must constantly and continually reassess the situation before them, even while they continue to battle the blaze.

\section{Findings}

To better understand the different sensemaking needs presented by simultaneous complexity and volatility, we can turn to the sensemaking model of Jennings and Greenwood (2003), which was adapted from Weick (1979). The model is straightforward and includes all seven characteristics of sensemaking (Weick, 1995), and, as noted by Weber and Glynn (2006), it also highlights enactment's role in institutional change (Weick, Sutcliffe, \& Obstfeld, 2005). As shown in Figure 2, some ecological change triggers that something new needs to be considered. From this first sensemaking impulse, sensemakers introduce variation into the environment this is known as enactment. Then follows a process of retrospectively extracting cues, a process of selection in which sensemakers bracket and simplify any new information. Finally, the bracketed data is filtered through the lenses of sensemakers' own personal identity, in the search for plausibility, and the new meaning is retained. The model is not strictly linear, though it has a beginning - some triggering ecological change - and an end - the retention of meaning. Included in the model are various loops that signal sensemaking's ongoing nature and the impact of various processes on each other.

One of the hallmarks of high reliability organizing is a reluctance to simplify. Though simplification can help sensemakers move from the extraction of cues to the assigning of

Figure 2.

Conceptual model of sensemaking in organizing processes

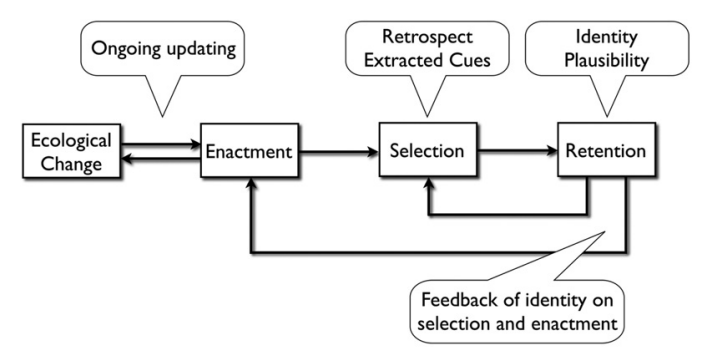

Source: Adapted from Jennings and Greenwood (2003, p. 202) 
meaning to those cues, and ultimately to retention of that meaning, especially in complex settings it is important to retain sensitivity to the abundance of cues. HROs seek requisite variety to ensure the complexity of their sensing matches the complexity of the environment. Simultaneous volatility throws wrenches into this process by continually triggering a return to the beginning of sensemaking (Figure 2). Each time an unpredictable and unstable ecological change is present in an environment, sensemakers are not only triggered to be sensitive to the new information, but they must also reassess their requisite variety in each instance, to ensure that their sensing matches the complexity of the situation. Such repeated reconsideration of the sensemaking process can effectively short-circuit the later stages of sensemaking, rather than trapping sensemakers in a loop of responding to ecological triggers that require continual reassessment of what is happening, rather than moving towards retention.

We see this "trigger trap" at work at Yarnell Hill in several ways. As in any fire, especially large scale, complex and volatile wildfires, weather reports are crucial in helping firefighters to maintain safe operations and, if possible, to stay ahead of the fire. At Yarnell Hill, Incident Command continually monitored the weather and communicated reports to those who were battling the fire. As noted in the investigation report (U.S. Forest Service, 2013), at 3:26 p.m. a National Weather Service update reported "an outflow boundary north of the fire that may produce north or northeast winds of 40 to $50 \mathrm{mph}$ " (p. 34). This report followed a 2:02 p.m. report of possible thunderstorms with "winds of 35 to $45 \mathrm{mph}$ out of the northeast" (p. 34). Any report of winds of that severity, or of potential thunderstorms - some of them likely generated by the fire itself - should have triggered renewed sensemaking by all who were fighting the fire. However, since the winds forecast in the 2:02 p.m. report did not materialize, Granite Mountain IHC may have considered the report to be a false alarm.

It is also possible that Granite Mountain treated the 3:26 p.m. report as the sensemaking trigger it should have been, but that they misinterpreted what they were sensing:

[The 3:26 p.m. report] appears to have carried less relevance in the crew's decision-making process, perhaps due to the wind shift (starting at about 3:50 p.m). that preceded the outflow boundary, or perhaps because of the time it took the outflow boundary to reach the south end of the fire (at 4:30 p.m.). It is possible they may have interpreted the early wind shift as the anticipated wind event. (U.S. Forest Service, 2013, p. 43)

Investigators surmise that a "bias for engagement" (U.S. Forest Service, 2013, p. 47) could have influenced Granite Mountain, by desensitizing them to the report. Might their decision to unknowingly move into the path of the fire have been due to a desire to break free from the trigger trap of repeated and varied weather reports, especially given that the reports had not materialized as they had expected? Investigators also noted that repeated reports of greatly heightened risk of wildfire in the two months preceding Yarnell Hill, alongside the apparent false alarms of the 2:02 p.m. and 3:26 p.m. reports, could have led to a desensitization of future reports (U.S. Forest Service, 2013, p. 48). This may have resulted in an unintended reduction in Granite Mountain's requisite variety as they ignored the ecological change presented by the 3:26 p.m. report and moved to later stages of their sensemaking.

The Granite Mountain crew made another decision that would reduce requisite variety, to calamitous ends. They decided to move their location to Incident Command without radioing this decision. In particular, requisite variety is handicapped when leaders are not able to gather sufficient and ongoing data about their organization and the situations it is facing. The lack of ongoing radio contact with the Granite Mountain crew resulted in Incident Command managers committing to the notion of the crew's safety, rather than continually updating their sensemaking by constantly extracting cues about the situation.
Collapse of sensemaking at Yarnell Hill 
EJMS

25,2

88

This simplification - believing that the crew was safe - meant that crucial resources were not deployed in time to save them. Here we see the trigger trap operating in a different manner - Granite Mountain IHC may have ceased updating Command on their location because they believed they were out of harm's way and also wanted to relieve "Operations from having to attend to another detail on an already busy fire” (U.S. Forest Service, 2013, p. 51). When the Granite Mountain crew radioed that they were "in the black" (U.S. Forest Service, 2013, p. 1), others supposed they would stay there, thus pre-empting any potential triggering from future location updates they assumed would not be forthcoming.

Based on the Jennings and Greenwood (2003) model of sensemaking (Figure 2), we can strengthen our model of simultaneous volatility and complexity (Figure 1) by examining the primary sensemaking processes that are active in various wildland firefighting scenarios. Although sensemaking is an ongoing procedure which moves sensemakers from equivocation to meaning, and although the processes within sensemaking are themselves ongoing and simultaneous, with various ongoing feedback loops, we can nevertheless highlight several of these processes in relation to different organizational situations.

We can now situate sensemaking within the model of simultaneous complexity and volatility, as represented in Figure 3. When volatility is low, there are relatively few ecological changes, especially the sort of unpredictable or unstable changes that would trigger firefighters' need to restart the sensemaking process and lead them to consider what new information needs to be considered. Sensemaking activities in these situations are focused more on the later stages in the Jennings and Greenwood (2003) model of sensemaking - where sensemakers move away from equivocality and towards retention. In situations characterized by low complexity and low volatility (lower left quadrant of Figure 3), sensemakers find themselves primarily in the retention phase of the sensemaking model. During this late stage of the model, extracted cues are filtered through the lenses of identity and plausibility and meaning is stored away for retention in memory. In situations of high complexity and low

Figure 3.

Sensemaking processes in situations of simultaneous volatility and complexity

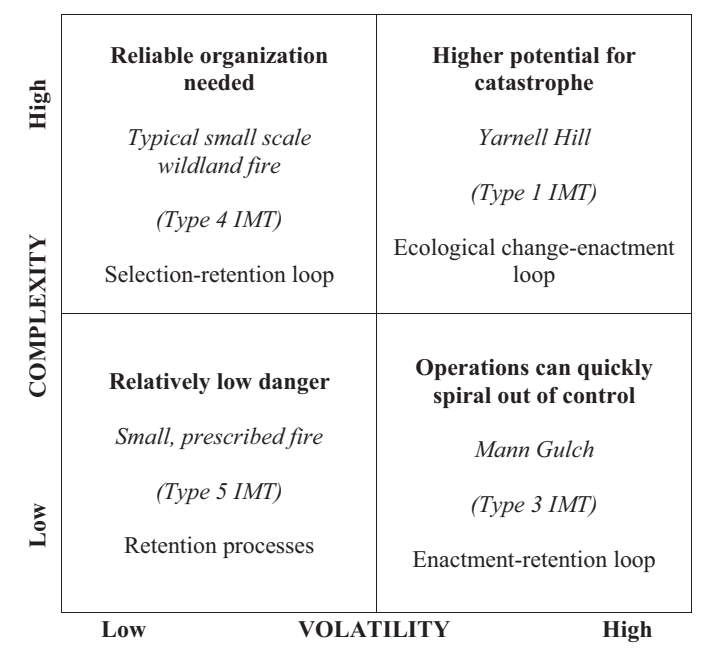

Source: Adapted from Jennings and Greenwood (2003); "Wildland Fire: Incident Command System Levels" (2017) 
volatility (upper left quadrant of Figure 3), the primary sensemaking activities are extended to the selection-retention loop, as sensemakers give more attention to the ongoing extraction of cues as they monitor and fight the fire. An example of this selection would be firefighters communicating with command about changes in the fire's direction and intensity.

On the other hand, high volatility broadens firefighters' sensemaking through constant and unpredictable ecological change. Each of these changes triggers firefighters to consider new information, constantly moving them back towards the beginning of the sensemaking model. In situations of low complexity and high volatility (lower right quadrant of Figure 3), sensemakers experience heightened awareness of the ways their actions impact the environment around them. An example of this enactment is when Wag Dodge, who saw that the Mann Gulch fire had jumped the gulch, told the men behind him to drop their heavy tools and run (Maclean, 1992, p. 71). As Weick (1993) explains, the command to drop one's tools and run resulted in an identity crisis: "A fire crew that retreats from a fire should find its identity and morale strained" (p. 637). A further example of enactment at Mann Gulch happened when Dodge figured they would never outrun the fire and so stopped running and lit an "escape fire" in the grass in front of him, telling the others to jump into the burnt portion, which everyone else thought was madness (Maclean, 1992, p. 92). Although this escape fire was to save Dodge's life, the others lamented his introduction of additional lethal fire into their environment and continued running towards the ridge above. The unpredictability of change in Mann Gulch caused real difficulty for the firefighters, especially as their actions enacted further change into the environment.

In situations of both high complexity and high volatility (upper right quadrant of Figure 3), continuous ecological change repeatedly triggers a return to the beginning of the sensemaking process. An example of this type of ecological change is the Yarnell Hill fire generating its own weather as it burned - including boundary formation "due to the intense heat coming off the surface, terrain interactions, and significant mid-level wind shear found above" (U.S. Forest Service, 2013 , p. 70). In such volatile conditions, it is not sufficient to just understand the weather in the area surrounding the fire - firefighters must also remain constantly alert to ways the fire itself can generate even more volatile weather, including thunderstorms and high winds. These unpredictable ecological changes continually move firefighters back to the beginning of the sensemaking process, making it increasingly more difficult to move to later stages. It is only when firefighters contain a wildfire that ecological change lessens and they can focus more intently on putting it out. As unexpected ecological changes become fewer in number, sensemakers are able to move through sensemaking processes towards retention.

To better understand the ways ecological changes can trap sensemakers at the beginning of the sensemaking process, we need to better understand how triggers work. Louis (1980) explains that "Discrepant events, or surprises, trigger a need for explanation, or post-diction, and, correspondingly, for a process through which interpretations of discrepancies are developed" (p. 241). But how do people respond to these surprises? They address the discrepancy by applying learned meanings from past experiences, at which time "understandings of actors, actions, and settings are updated and predictions about future experiences in the setting are revised" (p. 241). Louis provides a very important caveat, however: "It is crucial to note that meaning is assigned to surprise as an output of the sense-making process, rather than arising concurrently with the perception or detection of differences." (p. 241). In other words, the full meaning and importance of any surprise cannot be realized until the end of the sensemaking process, retention.

We can now begin to understand how disruptive unpredictable and repeated ecological change can be for those who are trying to figure out what it means. In the case of firefighters 
EJMS

25,2

who are fighting to contain wildland fires, the ongoing and volatile ecological changes continuously trigger in them the need for renewed sensemaking. Not only do weather changes present serious and dangerous consequences for firefighters, the fact that the fire may be generating its own constantly changing weather greatly increases the seriousness with which the changes must be addressed. In such scenarios, firefighters are confronted with the need for careful sensemaking again and again, each new trigger signifying that something vital must be considered. These constant ecological changes can thus trap firefighters at the beginning of sensemaking and can prevent them from moving to later stages in the sensemaking process.

Our analysis illustrates the confounding effects of simultaneous complexity and volatility in organizational settings. Dealing with volatile situations is difficult enough, as sensemakers work to confront unstable and unexpected changes. The addition of operational complexity substantially increases the difficulty of finding reliable solutions to problems that the organization is facing. When environmental volatility (constant ecological change) continually triggers a need for renewed sensemaking, people can get trapped in the earliest stages of sensemaking, and become unable to move towards retention. This means that a deeper understanding of the situation - including the meaning of the triggers themselves (Louis, 1980) - can be delayed, or even prevented altogether. Because it is in the later stages of sensemaking that we move from equivocality to retention of meaning, being trapped at the earlier stages of sensemaking severely limits understanding and any resultant action that can only occur after reliable sensemaking has taken place (and meaning has been retained in some plausible manner). Trigger traps, therefore, can effectively paralyze sensemakers, by preventing them from sufficiently understanding the complexity and volatility of their environments and then crafting appropriate responses.

Understanding the confounding effects of volatility and complexity begs the question of how organizations should respond. Here again, requisite variety plays a key role. Although it is understandable that Granite Mountain IHC might have restricted communication about their location to reduce the complexity of radio communication, that decision ultimately crippled Incident Command's ability to respond with lifesaving resources that were literally flying overhead. This suggests that organizations that find themselves confronted by simultaneous volatility and complexity - in which repeated ecological triggers can trap sensemakers and limit their ability to make full and reliable environmental assessments - might be very explicit in ensuring the complexity of their sensing mechanisms effectively match the needs of the environment. In the modern world, technology will surely play an ever-increasing role in maintaining requisite variety, by, for instance, automatically communicating the GPS location of every firefighter and every resource to Incident Command in real time. However, in situations where such technology is not readily available, leaders might continually monitor their understanding of the environmental complexity and require a corresponding level of reporting and feedback. While this will increase the complexity of the data that leaders receive - thus adding cognitive load and complicating their own sensemaking - it could also provide vital support to those trapped by repeated ecological triggers.

\section{Limitations, implications and conclusions}

This study is limited in several ways. First, our dataset only consists of secondary data, based on reports of an event that occurred six years ago. Our findings may have been bolstered, or challenged, had we directly interviewed anyone who had been involved in the firefighting efforts at Yarnell Hill. Second, our decision to focus primarily on the intersection of volatility and complexity, while setting aside uncertainty and ambiguity, frames the way that we analyze sensemaking. Although we believe that our reasoning for isolating 
uncertainty and ambiguity from the current study is justifiable, that choice reduces the total set of findings by simplifying the number of variables we considered.

With these caveats in mind, our fundamental insight is important, namely: certain conditions faced by sensemakers can trap them in loops which they might not even realize. These traps may even prevent their advancement into later stages of the sensemaking process and, ultimately, prevent positive outcomes. In most organizations, relatively few circumstances include life-or-death outcomes; however, this instance offers all-important lessons, because this was one high-profile case which did lead to a life-or-death outcome. Our analysis deepens the scholarly understanding of enactment, especially regarding the ways that sensemakers can effectively be paralyzed by their early sensemaking in volatile and complex environments. This is an important nuance for sensemaking models - where the usual cycle of enactment, selection, and retention (Weick, 1979) may be confounded by the vicious cycle of trigger traps in early stages, thus effectively preventing sensemakers from ever reaching the latter stage of retention.

Trigger traps thus pose a chilling and a perilous omen for organizations. Environments characterized by heightened volatility and complexity - meaning they are most in need of careful and nuanced sensemaking, as in wildland firefighting (Whiteman \& Cooper, 2011) may contain conditions that short-circuit sensemaking before it ever has a chance to produce meaning and understanding. It is precisely these situations that most call for high reliability - whereby the professionals tasked with making sense of it all could find themselves incapacitated, even to tragic ends. In such situations, priorities will necessarily shift from achieving organizational objectives - putting out the fires - through to protecting and safeguarding organizational members from harm. This is the epitome of enactment the very presence of people in environments introduces increased equivocality into those environments (Weick, 1979). In other words, the very presence of hotshots in a fire makes the fire itself more dangerous - as they then have to fight not only to contain the fire, but also to keep the firefighters themselves safe. Trigger traps make enactment even more fraught, as the hotshots themselves are paralyzed.

Once again, we might consider what this portends for organizations more broadly. First, it is important to have a valid understanding of the environment (Daft \& Weick, 1984). For not all situations or settings are characterized by heightened volatility or complexity. If an organization finds itself in a volatile and/or complex situation - such as in a global health pandemic characterized by rapidly changing forecasts and potentially deadly consequences for decision makers - then members need to be especially vigilant for the ways that constant triggers might trap them in the early stages of sensemaking. Once an organization diagnoses the likelihood of trigger traps, it could then appoint a devil's advocate (Schwenk, 1984) - someone whose task is to take a contrary point of view and explore options that might have been ruled out by later triggers.

Another way organizations can respond is by being ever more intentional about their fidelity to their core mission and the action principles (Gioia \& Thomas, 1996). In Yarnell, this could have led Granite Mountain to rank Incident Command's need to know about the location of all resources on the fire higher than Granite Mountain's bias for engagement and the desire to reduce radio traffic. For instance, when universities are weighing options for resuming classes in the midst of Covid-19, this could result in ranking their commitment to educating students - including those from underserved populations - with their desire to keep students, faculty, and staff safe (Meng, Hua, \& Bian, 2020) to follow guidance from government agencies and officials; to consider feedback from parents and guardians; and to assuage the fears of students themselves; etc. A clear articulation of core operational and mission values, alongside priorities and goals - an articulation that may likely need to be 
repeatedly restated and confirmed, a process known as overlearning (Krueger, 1929) - could help organizations avoid harmful or even fatal missteps. In high reliability organizing, the result is a reluctance to simplify results in sensing operations that match the complexity of the surrounding environment; trigger traps can short-circuit reliability by foiling the ability of sensemakers to move beyond enactment to stages of selection and retention. Furthermore, fidelity to core values may help organizations retain some of this resiliency.

Over 25 years ago, Weick (1993) suggested that understanding the Mann Gulch tragedy could help us "forestall similar disasters in other organizations," (p. 634) - yet we find ourselves writing another requiem for firefighters whose deaths should have been avoided. This study provides a vital correction to our understanding of high reliability organizing by identifying the way triggers can trap sensemakers - even to a deadly end. In increasingly complex and volatile environments, this knowledge could help us draw ever nearer to Weick's hopeful claim. Additionally, in deriving such insights and proactively applying them, we also continue to honor the 19 whose lives were lost that terrible day on Yarnell Hill.

\section{References}

Ahmadjian, C. L., \& Robinson, P. (2001). Safety in numbers: Downsizing and the deinstitutionalization of permanent employment in Japan. Administrative Science Quarterly, 46(4), 622-654. doi: $10.2307 / 3094826$.

Alvesson, M., \& Sandberg, J. (2013). Has management studies lost its way? Ideas for more imaginative and innovative research. Journal of Management Studies, 50(1), 128-152. doi: 10.1111/j.14676486.2012.01070.x.

Barton, M. A., \& Sutcliffe, K.M. (2009). Overcoming dysfunctional momentum: Organizational safety as a social achievement. Human Relations, 62(9), 1327-1356. doi: 10.1177/0018726709334491.

Barton, M. A., Sutcliffe, K. M., Vogus, T. J., \& DeWitt, T. (2015). Performing under uncertainty: Contextualized engagement in wildland firefighting. Journal of Contingencies and Crisis Management, 23(2), 74-83. doi: 10.1111/1468-5973.12076.

Bennett, N., \& Lemoine, G.J. (2014). What a difference a word makes: Understanding threats to performance in a VUCA world. Business Horizons, 57(3), 311-317. doi: 10.1016/j.bushor.2014.01.001.

Berthod, O., \& Müller-Seitz, G. (2018). Making sense in pitch darkness: An exploration of the sociomateriality of sensemaking in crises. Journal of Management Inquiry, 27(1), 52-68. doi: $10.1177 / 1056492616686425$.

Bigley, G. A., \& Roberts, K. H. (2001). The incident command system: High-reliability organizing for complex and volatile task environments. Academy of Management Joumal, 44(6), 1281-1299. doi: $10.2307 / 3069401$.

Brown, S. L., \& Eisenhardt, K. M. (1997). The art of continuous change: Linking complexity theory and time-paced evolution in relentlessly shifting organizations. Administrative Science Quarterly, 42(1), 1-34. doi: 10.2307/2393807.

Busby, J., \& Iszatt-White, M. (2014). The relational aspect to high reliability organization. Journal of Contingencies and Crisis Management, 22(2), 69-80. doi: 10.1111/1468-5973.12045.

Colville, I., Pye, A., \& Carter, M. (2013). Organizing to counter terrorism: Sensemaking amidst dynamic complexity. Human Relations, 66(9), 1201-1223. doi: 10.1177/0018726712468912.

Cornelissen, J. P., Mantere, S., \& Vaara, E. (2014). The contraction of meaning: The combined effect of communication, emotions, and materiality on sensemaking in the stockwell shooting. Journal of Management Studies, 51(5), 699-736. doi: 10.1111/joms.12073.

Daft, R. L., \& Weick, K. E. (1984). Toward a model of organizations as interpretation systems. Academy of Management Review, 9(2), 284-295. Retrieved from: https://doi.org/10.5465/amr.1984.4277657 
Davis, G. F. (2015). Editorial essay: What is organizational research for? Administrative Science Quarterly, 60(2), 179-188. doi: 10.1177/0001839215585725.

Dickman, K. (2015). On the burning edge: A fateful fire and the men who fought it. New York, NY: Ballantine Books.

Gephart, R. P. (1993). The textual approach: Risk and blame in disaster sensemaking. Academy of Management Journal, 36(6), 1465-1514.

Gioia, D. A., \& Thomas, J. B. (1996). Identity, image, and issue interpretation: Sensemaking during strategic change in academia. Administrative Science Quarterly, 41(3), 370-403.

Grant, R. M. (2003). Strategic planning in a turbulent environment: Evidence from the oil majors. Strategic Management Journal, 24(6), 491-517.

Heath, M., \& Porter, T. (2019). Sensemaking through a storytelling lens: Physician perspectives of health information exchange. Qualitative Research in Organizations and Management: An International Journal, 14(4). doi: 10.1108/QROM-05-2018-1648.

Heilman, W., Bian, X., Clark, K., \& Zhong, S. (2019). Observations of turbulent heat and momentem fluxes during wildland fres in forested environments. Journal of Applied Meteorology and Climatology, 58(4), 813-829. doi: 10.1175/JAMC-D-18-0199.1.

Industrial Commission of Arizona: Division of Ocupational Safety and Health (2013). Citation and notification of penalty. (Inspection number: 317242683). Arizona.

Ishak, A. W., \& Williams, E. A. (2017). Slides in the tray: How fire crews enable members to borrow experiences. Small Group Research, 48(3), 336-364. doi: 10.1177/1046496417697148.

Jennings, P. D., \& Greenwood, R. (2003). Constructing an iron cage: Institutional theory and enactment. R.I. Westwood, \& S.R. Clegg, (Eds.), Debating organization: Point-counterpoint in organization studies, pp. 195-207. Malden, MA: Blackwell.

Keller, P., Weick, K. E., Sutcliffe, K. M., Saveland, J., Lahey, L., \& Thomas, D. et al. (2004). Managing the unexpected in prescribed fire use operations: A workshop on the high reliability organization, (pp. 80). Santa Fe, NM: USDA Forest Service.

Kosinski, J., Flynn, S., Nolan, K., \& Singer, E. W. (2017). Only the brave, D.B. Pictures, (Producer). Columbia Pictures.

Krueger, W. C. F. (1929). The effect of overlearning on retention. Journal of Experimental Psychology, 12(1), 71-78. Retrieved from: https://doi.org/10.1037/h0072036

Lonnie, T. P. Thompson, T. L. Loach, J.A. Delfin, T., \& Przybylek, C. S. (2000). Cerro Grande prescribed fire investigation report.

Louis, M. R. (1980). Surprise and sense making: What newcomers experience in entering unfamiliar organizational settings. Administrative Science Quarterly, 25(2), 226-251. doi: 10.2307/2392453.

McDonough, B., \& Talty, S. (2016). My lost brothers: The untold story by the yarnell hill fire's lone survivor, New York, NY: Hachette Books.

Maclean, N. (1992). Young men, \& fire, Chicago, IL: University of Chicago Press.

Maitlis, S., \& Christianson, M. (2014). Sensemaking in organizations: Taking stock and moving forward. The Academy of Management Annals, 8(1), 57-125. doi: 10.1080/19416520.2014.873177.

Maitlis, S., \& Sonenshein, S. (2010). Sensemaking in crisis and change: Inspiration and insights from Weick (1988). Journal of Management Studies, 47(3), 551-580.

Meng, L., Hua, F., \& Bian, Z. (2020). Coronavirus disease 2019 (COVID-19): Emerging and future challenges for dental and oral medicine. Journal of Dental Research, 99(5), 481-487. Retrieved from: https://doi.org/10.1177/0022034520914246

Mohit, E., Kelso, B., \& Florman, K. (2014/2016). From tragedy to recovery: The yarnell hill wildfire of 2013, 6th ed., San Bernadino, CA: Yarnell-Peeples Valley Chamber of Commerce.

Murphy, R. M. (1997). Overview of strategic management leading and managing in the strategic arena: A reference text, pp. 436-463. Carlisle Barracks, PA: Army War College. 
EJMS 25,2

Parrish, C. S. C., D. (2019). What's the story here? The effect of volatility on university leader sensemaking of undocumented student access. European Journal of Management Studies, 24(2), 53-78. doi: 10.5455/EJMS.

Rijpma, J. A. (1997). Complexity, tight-coupling and reliability: Connecting normal accidents theory and high reliability theory. Journal of Contingencies, \& Crisis Management, 5(1), 15-23.

Rochlin, G. I., La Porte, T., \& Roberts, K. H. (1987). The self-designing high reliability organization: Aircraft carrier flight operation at sea. Naval War College Review, 40, 76-90.

Rosenkrance, L. K., Reimers, M. A., Johnson, R. A., Webb, J. B., Graber, J. H., Clarkson, M., Werth, P., Husari, S., Mangan, D., \& Putnam, T. (1994). Report of the South canyon fire accident investigation team, Glenwood Springs: CO.

Salancik, G. R. (1977). Commitment is too easy. Organizational Dynamics, 6(1), 62-80. doi: 10.1016/00902616(77)90035-3

Santos, F. (2016). The fire line: The story of the granite Mountain hotshots, New York, NY: Flatiron Books.

Schabram, K., \& Maitlis, S. (2017). Negotiating the challenges of a calling: Emotion and enacted sensemaking in animal shelter work. Academy of Management Journal, 60(2), 584-609. doi: 10.5465/amj.2013.0665.

Schwenk, C. R. (1984). Devil's advocacy in managerial decision-making. Journal of Management Studies, 21(2), 153-168. Retrieved from: https://doi.org/10.1111/j.1467-6486.1984.tb00229.x

Seidl, D., \& Werle, F. (2018). Inter-organizational sensemaking in the face of strategic meta-problems: Requisite variety and dynamics of participation. Strategic Management Journal, 39(3), 830-858. doi: 10.1002/smj.2723.

Selznick, P. (1957). Leadership in administration: A sociological interpretation, New York, NY: Harper, \& Row.

Stackman, R. W., \& Hannah, D. R. (2017). Generative curiosity: Introducing JMI's newest section. Journal of Management Inquiry, 26(1), 112-115.

U.S. Forest Service (2013). Yarnell hill fire: Serious accident investigation report.

Useem, M., Cook, J. R., \& Sutton, L. (2005). Developing leaders for decision making under stress: Wildland firefighters in the South canyon fire and its aftermath. Academy of Management Learning, \& Education, 4(4), 461-485. doi: 10.5465/amle.2005.19086788.

Vogus, T. J., Rothman, N. B., Sutcliffe, K. M., \& Weick, K. E. (2014). The affective foundations of highreliability organizing. Journal of Organizational Behavior, 35(4), 592-596. doi: 10.1002/job.1922.

Weber, K. E., \& Glynn, M. A. (2006). Making sense with institutions: Context, thought and action in Karl Weick's theory. Organization Studies, 27(11), 1639-1660.

Weick, K. E. (1979). The social psychology of organizing, Reading, MA: Addison-Wesley Pub. Co.

Weick, K. E. (1988). Enacted sensemaking. Journal of Management Studies, 25(4).

Weick, K. E. (1993). The collapse of sensemaking in organizations: The Mann Gulch disaster. Administrative Science Quarterly, 38(4), 628-652.

Weick, K. E. (1995). Sensemaking in organizations, Thousand Oaks, CA: Sage Publications.

Weick, K. E. (2001). Making sense of the organization, Oxford: Blackwell.

Weick, K. E. (2008). Sensemaking. nS. R. Clegg, \& J. R. Bailey, (Eds.), International encyclopedia of organization studies, pp. 1404-1407. Thousand Oaks, CA: Sage Publications.

Weick, K. E. (2010). Reflections on enacted sensemaking in the Bhopal disaster. Journal of Management Studies, 47(3), 537-550.

Weick, K. E. (2011). Organizing for transient reliability: The production of dynamic non-events. Journal of Contingencies and Crisis Management, 19(1), 21-27. doi: 10.1111/j.1468-5973.2010.00627.x.

Weick, K. E. (2016). 60th anniversary essay: Constrained comprehending: the experience of organizational inquiry. Administrative Science Quarterly, 61(3). doi: 10.1177/0001839216633453. 
Weick, K. E., \& Roberts, K. H. (1993). Collective mind in organizations: Heedful interrelating on flight decks. Administrative Science Quarterly, 38(3), 357-381. doi: 10.2307/2393372.

Weick, K. E., \& Sutcliffe, K. M. (2007). Managing the unexpected: Resilient performance in an age of uncertainty, 2nd ed., San Francisco, CA: Jossey-Bass.

Weick, K. E., \& Sutcliffe, K. M. (2015). Managing the unexpected: Sustained performance in a complex world, 3rd ed., Hoboken, NJ: Wiley, \& Sons.

Weick, K. E., Sutcliffe, K. M., \& Obstfeld, D. (2005). Organizing and the process of sensemaking. Organization Science, 16(4), 409-421.

Whiteman, W. E. (1998). Training and educating army officers for the 21st century: Implications for the United State military academy, Carlisle Barracks, PA: Army War College.

Whiteman, G. (2010). Management studies that break your heart. Journal of Management Inquiry, 19(4), 328-337. doi: 10.1177/1056492610370282.

Whiteman, G., \& Cooper, W.H. (2011). Ecological sensemaking. Academy of Management Journal, 54(5), 889-911. Retrieved from: https://doi.org/10.5465/amj.2008.0843

Wildland Fire: Incident Command System Levels (2017). Wildland fire - learning in depth. Retrieved from: www.nps.gov/articles/wildland-fire-incident-command-system-levels.htm

Williams, E. A., \& Ishak, A. W. (2018). Discourses of an organizational tragedy: Emotion, sensemaking, and learning after the Yarnell hill fire. Western Journal of Communication, 82(3), 296-314. doi: 10.1080/10570314.2017.1313446.

Zahra, S. A., Sapienza, H. J., \& Davidsson, P. (2006). Entrepreneurship and dynamic capabilities: A review, model and research agenda. Journal of Management Studies, 43(4), 917-955. doi: 10.1111/ j.1467-6486.2006.00616.x.

\section{Corresponding author}

Dan Parrish C.S.C. can be contacted at: parrishd@up.edu

For instructions on how to order reprints of this article, please visit our website: 